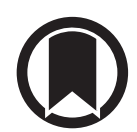

CrossMark

\title{
The European Sleep Apnoea Database (ESADA) ERS Clinical Research Collaboration: past, present and future
}

\author{
Maria R. Bonsignore ${ }^{1,2}$ and Jan Hedner ${ }^{3}$, on behalf of the ESADA study group ${ }^{4}$ \\ Affiliations: ${ }^{1}$ Biomedical Dept of Internal Medicine and Medical Specialties (DiBiMIS), University of Palermo, \\ Palermo, Italy. ${ }^{2}$ Institute of Biomedicine and Molecular Immunology (IBIM), National Research Council (CNR), \\ Palermo, Italy. ${ }^{3}$ Dept of Sleep Medicine, Respiratory Medicine and Allergology, Sahlgrenska University \\ Hospital and the University of Gothenburg, Gothenburg, Sweden. ${ }^{4} \mathrm{~A}$ full list of the current and past ESADA \\ collaborators and their affiliations can be found at the end of this article.
}

Correspondence: Maria R. Bonsignore, DiBiMIS, University of Palermo, Piazza delle Cliniche 2, 90100 Palermo, Italy. E-mail: marisađibim.cnr.it

@ERSpublications

The European Sleep Apnoea Database (ESADA) ERS Clinical Research Collaboration records data in over 25000 patients with OSA from 33 European countries, to conduct clinical research and improve OSA patient care and outcomes http://ow.ly/DuDf30lZRP6

Cite this article as: Bonsignore MR, Hedner J. The European Sleep Apnoea Database (ESADA) ERS Clinical Research Collaboration: past, present and future. Eur Respir J 2018; 52: 1801666 [https://doi.org/ 10.1183/13993003.01666-2018].

\section{The start of the European Sleep Apnoea Database}

The European Sleep Apnoea Database (ESADA) study began in 2007 as a joint project within the European Union (EU) Cooperation in Science and Technology (COST) Action B26 on obstructive sleep apnoea (OSA) and cardiovascular risk, as a network of nationally appointed sleep apnoea experts. At that time, there were few cohorts of OSA patients, mainly in the context of epidemiological studies in the general population [1-6]. The COST Action only provided funding for networking, and each participating centre entered data into the web-based database on a voluntary basis. Collected data included anthropometrics, results of blood tests, current medications, and sleep data derived from full polysomnography or cardiorespiratory nocturnal monitoring, according to the diagnostic procedure chosen by the physician. Importantly, quality controls of the dataset were performed at regular intervals since the start of the project.

During the first 2 years of the ESADA project, 5000 patients had been enrolled by 22 European sleep laboratories and stored at the coordinating centre in Gothenburg, Sweden [7]. The study continued after the end of the COST Action in 2010, thanks to financial support by the industry, and both the number of participating centres and the number of patients grew to reach the current figures of 33 and 25000, respectively.

Before the approval of the ESADA project as a European Respiratory Society (ERS) Clinical Research Collaboration (CRC) in 2015, some important changes occurred. First, members of the ESADA group gathered each year in late winter or early spring in different European sleep centres for a 2-3-day meeting to discuss current and new projects and to work on manuscripts. Such meetings, as well as short-term exchanges of young researchers between ESADA laboratories, have strengthened the relationship between members and provided a creative, generous and friendly environment, while increasing the research productivity of the network. In 2014, four studies were published, reporting cross-sectional analyses on blood pressure [8], metabolic disorders [9, 10] and car accidents [11]. Secondly, a new generation of clinicians and scientists became involved in the ESADA study group and contributed enthusiastically to 
patient recruitment and new research projects, setting the premises for continuity of the project beyond the "founders". Thirdly, it was recognised that it was important to set up a longitudinal cohort rather than continuing with recruitment of new patients at a high rate. Indeed, the aim of the first CRC in 2015 was to implement follow-up visits and longitudinal studies, and data on renal function [12] and body weight change [13] according to OSA treatment during follow-up have been recently published. Meanwhile, digging into the dataset in cross-sectional studies continued, with published research papers on methodological issues related to the diagnostic method [14], the association of OSA with chronic kidney disease [15], asthma [16] or dyslipidaemia [17], and the search for clinical phenotypes [18].

\section{Where does ESADA currently stand?}

The approval of the CRC by the ERS, and its recent renewal, greatly increased the visibility and prestige of ESADA worldwide, together with the cohesion and motivation of its members, in particular the commitment for further improvements, especially regarding OSA patient care and patient outcomes, which represent the ultimate goal of the ESADA project.

Current research projects include the association of OSA with cancer, definition of risk associated with mild OSA, and differences in OSA phenotypes between European countries. At the time of writing (in August 2018), there are more than 37000 visits in the database, including first and follow-up visits. The monthly inclusion rate is $\sim 150-200$ patients and the scientific activity is high (13 abstracts accepted in international conferences in 2018 and several manuscripts in preparation/submission). The ESADA serves as a reference database on European sleep apnoea patients and continues to provide a bridge for education and knowledge transfer between the various participating centres. Following early enabling grants, the ESADA has remained a low-budget study based on strong voluntary input from participating centres.

\section{The future of the ESADA CRC}

We would like to extend the network to include new sleep centres from countries not yet represented in the current CRC. Involvement of OSA patient organisations will be promoted with the help of the European Lung Foundation, in order to jointly address the problem of treatment acceptance and non-adherence, a highly hot topic nowadays. While collection of longitudinal data will continue, contacts were established with other clinical cohorts of OSA patients in Europe during a workshop held in Palermo, Italy, in early July 2018, when the possibility of joint projects on "big data" was discussed and awaits approval by the members of ESADA and other cohorts to proceed to formal agreements.

The current debate $[19,20]$ on randomised controlled trials (RCTs) to evaluate the effects of continuous positive airway pressure (CPAP) on cardiovascular risk suggests that new study designs, adopted to obtain clinically relevant results applicable to different subgroups of patients, should be introduced. Inclusion of OSA patients in long-term RCTs on the effects of OSA treatment has, for ethical reasons, been limited to non-sleepy patients who are poorly compliant to CPAP treatment. Negative results of RCTs could therefore be secondary to poor treatment adherence, rather than to inefficacy of treatment [19]. In this regard, the ESADA CRC could be a powerful instrument to collect a large amount of longitudinal data in OSA patients in the European context. Adoption of the specific methodology required in pragmatic trials will be the next challenge for ESADA and other investigators in the years to come.

There are some critical issues that determine the sustainability of the ESADA project in the long term. We need to develop strategies to maintain high data quality and enable new research activities related to the database. Funding may be provided by public and academic institutions or by collaborations with industry. We plan to submit EU research or public health projects, and cooperation with other cohorts will help to reach the critical mass necessary to cover the entire European area. Again, the CRC is a very good opportunity to pursue this goal, not only for the visibility provided by the endorsement of a leading society like the ERS, but also for the practical support in submission of big projects. With these prospects, we anticipate a bright future for the highly successful collaborative ESADA project.

Collaborators: M.R. Bonsignore and J. Hedner are Chairs of the ESADA Clinical Research Collaboration. Collaborators in the ESADA project (current and past) by country and sleep centre were as follows. Belgium: J. Verbraecken and E. Petiet (Multidisciplinary Sleep Disorders Centre, Antwerp University Hospital and University of Antwerp, Antwerp); D. Rodenstein (Cliniques Universitaires Saint-Luc, Brussels). Croatia: Z. Dogas and T. Galic (Sleep Medicine Center, Dept of Neuroscience, University of Split School of Medicine, Split). Czech Republic: O. Ludka (Dept of Cardiology, University Hospital Brno and International Clinical Research Center, St Ann's University Hospital, Brno); M. Pretl (Centre for Sleep and Waking Disorders, Dept of Neurology, First Faculty of Medicine, Charles University, Prague, and Inspamed, Neurology and Sleep Laboratory, Prague). Finland: U. Anttalainen and T. Saaresranta (Division of Medicine, Dept of Pulmonary Diseases, Turku University Hospital and Sleep Research Centre, Dept of Pulmonary Diseases and Clinical Allergology, University of Turku). France: P. Levy and J-L. Pépin (Université Grenoble Alpes, INSERM HP2 (U1042) and Grenoble University Hospital, Grenoble); P. Escourrou and G. Roisman (Service d'Éxplorations Fonctionnelles Multidisciplinaires and Unité de Médecine du Sommeil, Hospital Antoine Beclere, Clamart). Germany: 
I. Fietze and T. Penzel (Schlafmedizinisches Zentrum, Charité - Universitätsmedizin Berlin); R. Schulz (Sleep Disorders Centre, University of Giessen, Lung Centre, Giessen); H. Hein (Sleep Disorders Center, St Adolf Stift, Reinbeck). Greece: P. Steiropoulos (Sleep Unit, Dept of Pneumonology, Democritus University of Thrace, Alexandroupolis); G. Trakada (Pulmonary Medicine, National and Kapodistrian University of Athens, Athens); I. Bouloukaki and S. Schiza (Sleep Disorders Unit, Dept of Respiratory Medicine, Medical School, University of Crete); A. Pataka (Respiratory Failure Unit, G. Papanikolaou Hospital, Thessalonika). Ireland: W.T. McNicholas (Dept of Respiratory Medicine, St Vincent's University Hospital, Dublin); S. Ryan (Pulmonary and Sleep Disorders Unit, St Vincent's University Hospital, Dublin). Israel: L. Lavie and P. Lavie (Centre for Sleep Medicine, Technion Institute of Technology, Haifa). Italy: C. Lombardi and G. Parati (Istituto Auxologico Italiano, Ospedale San Luca, Milan); M.R. Bonsignore (Biomedical Department of Internal Medicine and Medical Specialties (DiBiMIS), Section of Pneumology, University of Palermo, and CNR Institute of Biomedicine and Molecular Immunology, Palermo); O. Marrone (CNR Institute of Biomedicine and Molecular Immunology, Palermo). Latvia: A. Vitols (Institute of Cardiology, University of Latvia, Riga). Lithuania: G. Varoneckas (Institute Psychophysiology and Rehabilitation, Palanga). Norway: J.A. Kvamme (Sleep Laboratory, ENT Department, Førde Central Hospital, Førde). Poland: P. Sliwinski and R. Plywaczewski (Institute of Tuberculosis and Lung Diseases, Dept of Diagnosis and Treatment of Respiratory Failure, Warsaw); P. Bielicki and J. Zielinski (Dept of Internal Medicine, Pneumonology and Allergology, Warsaw Medical University, Warsaw). Portugal: R. Staats (Dept of Respiratory Medicine, Hospital de Santa Maria, Lisbon); M. Drummond and M. van Zeller (Pulmonology Dept, Hospital São João, Medicine Faculty of Porto University, Porto). Slovakia: P. Joppa and R. Tkacova (Dept of Respiratory Medicine and Tuberculosis, Faculty of Medicine, P.J. Safarik University and L. Pasteur University Hospital, Kosice). Spain: J.M. Montserrat (Hospital Clinic i Provincial de Barcelona, Barcelona, IDIBAPS Barcelona and CIBERes, Madrid); J.F. Masa (Hospital San Pedro de Alcàntara, Cáceres); F. Barbé (Servei Pneumologia Hospital Arnau de Vilanova and Hospital Santa Maria, Lleida, and CIBERes, Madrid). Sweden: J. Hedner and L. Grote (Dept of Sleep Medicine, Sahlgrenska University Hospital, Gothenburg). UK: B. Kent (Guy's and St Thomas' NHS Foundation Trust, Guy's Hospital, London); R.L. Riha (Dept of Sleep Medicine, Royal Infirmary Edinburgh). Turkey: O.K. Basoglu and M.S. Tasbakan (Dept of Chest Diseases, Ege University, Izmir). In addition, the following were centres in the start-up process: ENT Dept at Mainz University, Germany; Pulmonary Dept, University Hospital, Istanbul, Turkey.

Conflict of interest: M.R. Bonsignore has nothing to disclose. J. Hedner reports grants from ResMed, Respironics and Bayer, for conduct of the ESASA database, and an issued patent related to sleep apnoea treatment.

\section{References}

1 Young T, Palta M, Dempsey J, et al. The occurrence of sleep-disordered breathing among middle-aged adults. N Engl J Med 1993; 328: 1230-1235.

2 Bearpark H, Elliott L, Grunstein R, et al. Occurrence and correlates of sleep disordered breathing in the Australian town of Busselton: a preliminary analysis. Sleep 1993; 16: Suppl. 8, S3-S5.

3 Bixler EO, Vgontzas AN, Ten Have T, et al. Effects of age on sleep apnea in men: I. Prevalence and severity. Am J Respir Crit Care Med 1998; 157: 144-148.

4 Bixler EO, Vgontzas AN, Lin HM, et al. Prevalence of sleep-disordered breathing in women: effects of gender. Am J Respir Crit Care Med 2001; 163: 608-613.

5 Durán J, Esnaola S, Rubio R, et al. Obstructive sleep apnea-hypopnea and related clinical features in a population-based sample of subjects aged 30 to 70 yr. Am J Respir Crit Care Med 2001; 163: 685-689.

6 Redline S, Schluchter MD, Larkin EK, et al. Predictors of longitudinal change in sleep-disordered breathing in a nonclinic population. Sleep 2003; 26: 703-709.

7 Hedner J, Grote L, Bonsignore $M$, et al. The European Sleep Apnoea Database (ESADA): report from 22 European sleep laboratories. Eur Respir J 2011; 38: 635-642.

8 Tkacova R, McNicholas WT, Javorsky M, et al. Nocturnal intermittent hypoxia predicts prevalent hypertension in the European Sleep Apnoea Database cohort study. Eur Respir J 2014; 44: 931-941.

9 Kent BD, Grote L, Bonsignore MR, et al. Sleep apnoea severity independently predicts glycaemic health in nondiabetic subjects: the ESADA study. Eur Respir J 2014; 44: 130-139.

10 Kent BD, Grote L, Ryan S, et al. Diabetes mellitus prevalence and control in sleep-disordered breathing: the European Sleep Apnea Cohort (ESADA) study. Chest 2014; 146: 982-990.

11 Karimi M, Hedner J, Lombardi C, et al. Driving habits and risk factors for traffic accidents among sleep apnea patients - a European multi-centre cohort study. J Sleep Res 2014; 23: 689-699.

12 Marrone O, Cibella F, Pépin JL, et al. Fixed but not autoadjusting positive airway pressure attenuates the time-dependent decline in glomerular filtration rate in patients with OSA. Chest 2018; 154: 326-334.

13 Basoglu OK, Zou D, Tasbakan MS, et al. Change in weight and central obesity by positive airway pressure treatment in obstructive sleep apnea patients: longitudinal data from the ESADA cohort. J Sleep Res 2018; in press [https://doi.org/10.1111/jsr.12705].

14 Escourrou P, Grote L, Penzel T, et al. The diagnostic method has a strong influence on classification of obstructive sleep apnea. J Sleep Res 2015; 24: 730-738.

15 Marrone O, Battaglia S, Steiropoulos P, et al. Chronic kidney disease in European patients with obstructive sleep apnea: the ESADA cohort study. J Sleep Res 2016; 25: 739-745

16 Saaresranta T, Hedner J, Bonsignore MR, et al. Clinical phenotypes and comorbidity in European sleep apnoea patients. PLoS One 2016; 11: e0163439.

17 Bonsignore MR, Pepin JL, Anttalainen U, et al. Clinical presentation of patients with suspected obstructive sleep apnea and self-reported physician-diagnosed asthma in the ESADA cohort. J Sleep Res 2018; in press [https://doi. org/10.1111/jsr.12729].

18 Gündüz C, Basoglu OK, Hedner J, et al. Obstructive sleep apnoea independently predicts lipid levels: data from the European Sleep Apnea Database. Respirology 2018; in press [https://doi.org/10.1111/resp.13372].

19 Martinez-Garcia MA, Campos-Rodriguez F, Javaheri S, et al. Pro: continuous positive airway pressure and cardiovascular prevention. Eur Respir J 2018; 51: 1702400.

20 McEvoy RD, Kohler M. Con: continuous positive airway pressure and cardiovascular prevention. Eur Respir J 2018; 51: 1702721. 